\title{
Microwave-assisted Degradation of Polyvinyl Chloride Induced by Complexes of Transition Elements
}

\author{
Tariq Abdul-Jaleel \& Hameed Ali \& Ahmad Obeed
}

Department of Chemistry Desert research center

\section{Faculty of Science}

\section{University of Anbar}

\begin{abstract}
الخلاصة
اجري في هذا العمل دراسة تأثير اشعة المايكروويف على فلم من بولي كلوريد الفنيل

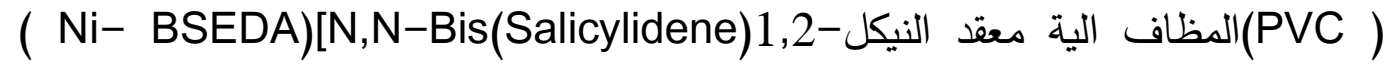

\% 0.1 \% $0.05,0.04,0.03,0.025$ 0نسبة مئوية 0.03 (diaminoethane] Nickel(II),

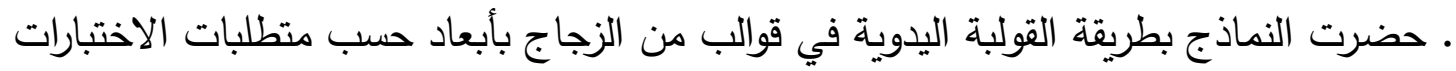

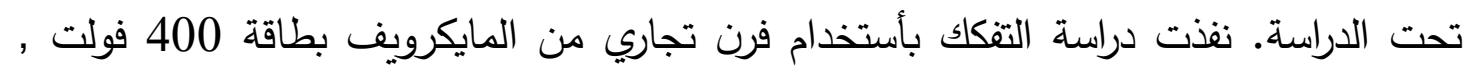

$$
\text { وبأزمان تشعيع ( } 0.0 \text {, 15, 30, } 60 \text { دقيقة). }
$$
\end{abstract}

تم متابعة عمليات التنكك باستخدام كروماتوكرافيا الغاز GC, ومطيافية ت تم حساب النقصان في الوزن الجزيئي ومعدله (Mn,

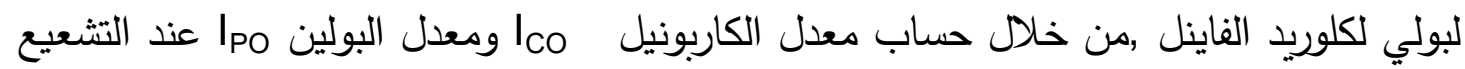
لمدة 60 دقيقة.

\section{ABSTRACT}

In this work, the presence of variable metals complex of [N,NBis(Salicylidene)1,2-[diaminoethane] Nickel(II), (Ni-BSEDA). And the PVC film were studied under the microwave radiation. The samples and complex metals salt were prepared using a hand molding casting with percentage $(0.0,0.025,0.03,0.04,0.05,0.1) \%$. Degradation studies were carried out using commercial microwave oven at constant power of $400 \mathrm{~W}$ for all experimental. The specimens were exposed to microwave radiation with multiple time $(0.0,15,30,60)$ minutes , A degradation were followed via the decreace in average of molecular weights $\left(\mathrm{Mw}^{-}\right.$ , $\left.\mathrm{Mn}^{-}\right)$

Presented at the second conference on Chemistry, University of Mosul, college of Education, 17-18 Novamber-2013. 
and increase of the growth of absorbency the carbonyl index $\mathrm{I}_{\mathrm{CO}}$ and polyene index $\mathrm{I}_{\mathrm{PO}}$ at the total time of 60 minutes .

Key Words: Microwave, Degradation, Polyvinyl Chloride, complexes

\section{INTRODUCTION}

Polyvinyl Chloride (PVC) is one of the most important polymers produced from petroleum, it occupies rank of the word production of the polymers.[1] There are two types of polyvinyl chloride ,first rigid polyvinyl chloride which is used in the manufacture of pipes and solid plates, second flexible polyvinyl chloride which is used in the manufacture of chips and coatings.[2]. The uses of this polymer in construction (pipes, window frames, etc.), packaging (food, blood bags) and wire coating have attracted much attention, besides favorable properties, such as non-flammability,[3] The degradation of PVC has been widely studied since 1940. Most of the early research works have been focused on the dehydrochlorination reactions to improve the thermal stability of PVC.[4]. The most serious problems encountered in poly(vinyl chloride) PVC processing is due to low Photo - thermal stability [5].. Environment receives large amounts of this polymer as a waste product that recent studies have focused on finding safe ways to disposed of these wastes.[6] and PVC responds to the degradation through optical, microwave, thermal, high-energy radiation gamma, $\mathrm{x}$ rays), [7], UV rays as well as microwave, Where the molecule of PVC absorbed the radiation [8].

Microwaves are electromagnetic waves of relatively low frequency) $10^{9}-10^{10}$ Herz) [9]. Microwave irradiation is a well-known method for heating and drying materials and is used in many private households and industrial applications for this purpose.[10] Offers several advantages over conventional heating such as non-contact heating(circus venting the decomposition of molecules close to the walls of their action vessel instantaneous and rapid heating ), resulting in a uniform heating of their action liquor, [11] microwave ovens operate with electromagnetic on ionizing radiation with frequencies between $300 \mathrm{MHz}$ and $300 \mathrm{GHz}$. The corresponding wave lengths span rang from $1 \mathrm{~mm}$ to $1 \mathrm{~m}$. [12]. There has always been a keen interest in the industrial application of microwave storm prove conventional processes microwave energy is an on ionizing energy source because it creates heat deep inside the materials. [13] These properties results in much shorter process time ,higher yield and better quality of products than that obtained by conventional processing techniques, [14-15]. In microwave activation the sample is exposed to electromagnetic fields at microwave frequencies.[16] Microwave activation occurs in times similar to that of light activation. [17]. When 
production of PVC for high stability there are two ways firstly used highpurity monomers and the second use of materials are called stabilizers, [18] materials are modified of chain reactions that lead to the degradation of the polymers was known free radical acceptors. [19]That added to PVC in ordered to increase the stability to heat, light and electro waves. [20] when PVC exposed to the degradation by heat, light or it microwave the $\mathrm{HCl}$ gas evolves and changes the color from yellow orange - brown to black, this decomposition lead to degeneration in the properties of the polymer and becomes brittle and subject to crush, [21] . The present study aimed to improve the degradation efficiency by microwave radiation (by a domestic microwave oven). For prepared PVC film was added a complex to follow its effect on the stability and degradation of $\mathrm{PV}$, , and calculating the adsorption of carbonyl index $\mathbf{I}_{\mathbf{c o}}$ and polyene index IPo, and the change in the molecular weights and molecular weight polydispersity (P.D) ( Mw- / Mn- .)

\section{EXPERIMENTAL}

\section{Materials and Procedure}

Chemicals ; The PVC were obtained from Petkim Co. ( Turkey). Tetra Hydro Furan THF, petroleum ether, Nickel chloride, Hydroxy Quinone, Benzene, was purchased from BDH . All chemicals were of analytical grade and used as received

Instrumentation; Nicolet FT-IR. IR100. Thermo Scientific .were used U.V- Vis. double beam cintaras 5 Spectrometer , M.Wts. were measured using Ostwald - Obblehode Viscometer . Microwave oven ( Korea), LG 2.15 GHz

\section{Preparation of ligand : $\mathrm{N}, \mathrm{N}$ disalycilydien - 1,2 - diamino methane (BSED):}

In $100 \mathrm{~mL}$ flask aniline diamine $(1.15 \mathrm{gm}, 0.025 \mathrm{~mol})$ dissolved in $30 \mathrm{ml}$ of absolute ethanol and $(6.1 \mathrm{~g}, 0.05 \mathrm{~mol})$ of salicylaldehyde was added to the mixture, then refluxed, for $1 \mathrm{~h}$ the mixture was cooled in an ice bath until the crystals precipitate, then recrystallized using absolute ethanol, and dried under vacuum at room temperature. FT-IR spectrum was recorded for product.

\section{Preparation of Complex [N,N-Bis(Salicylidene)1,2- [diaminoethane] Nickel(II):}

To the warm mixture of N,N-Bis(Salicylidene)1,2[diaminoethane], $(0.26 \mathrm{~g}, 0.001 \mathrm{~mol})$. which dissolved in $30 \mathrm{ml}$ of absolute ethanol, nickel chloride $(0.23 \mathrm{~g}, 0.001 \mathrm{~mol})$ in $20 \mathrm{~cm}^{3}$ of D.W was added. The mixture was stirred at room temperature for appropriate time until 
color of reaction mixture was changed from yellow to reddish. Then sodium bicarbonate solution was added and reflux for $2 \mathrm{~h}$. mixture was cooled at room temperature and crystals were obtained from filtrate. The crude product washed with (D.W) and recrystallized using absolute ethanol, and dryied under vacuum at $60-65 \mathrm{C}^{0}$. FT-IR spectrum and melting point M.P was recorded for product

Films preparation and Sampling; PVC was purified by dissolved in the chloroform and after that precipitated in petroleum etherm and determinate the M.Wt with Viscosity method. Film was prepared with blend PVC solution ( $10 \% \mathrm{w} / \mathrm{v}$ in THF) for several percentage of complex ( $0.0,0.025,0.03,0.04,0.05,0.1) \%$,were added to the solution( $3 \mathrm{CM}^{3}$ PVC and $1 \mathrm{CM}^{3}$ complex solution) on magnetic stirrers in medium velocity, after that the mixing solution poured into glass molds of dimensions $1 * 10 \mathrm{~mm}$, then casted on transparency sheet of thickness ( 65 \pm 5) $\mu \mathrm{m}$ and were allowed to dry under ambient conditions for $24 \mathrm{hrs}$. Free standing films were obtained, and furthermore dried in vacuum oven at $50 \mathrm{C}^{0}$ for $10 \mathrm{hrs}$.

Degradation Procedures.; A domestic microwave oven with magnetron source was used at constant power of $400 \mathrm{~W}$ was employed for all experiments. The degradation of ( PVC ) was conducted data constant of film,

The sample was placed at the center of the oven directly below the magnetron source and it was rotated on a turntable to avoid the temperature gradients in the degradation reactions. Samples were exposed to microwave with multiple time $(1530,60)$ minutes, and samples is periodically output from the device models due to M.Wt. Measurement, FT-IR and UV. Spectral

\section{Experimental Calculation:}

Analysis of degradation; Temporal absorption spectral changes during the degradation of film substrate the FT - IR was used, ( peaks at $\left.600-4000 \mathrm{CM}^{-1}\right)$ and than calculating the $\mathrm{C}=\mathrm{O}$ absorption at $1720 \mathrm{CM}^{-1}$ , peak at $1772 \mathrm{CM}^{-1}$ for chloro- ketone and polyene - $\mathrm{CH} 2-\mathrm{CH} 2-$ absorption at $1604 \mathrm{CM}^{-1}$ when estimated the $\mathbf{I}_{\mathbf{C O}}$ and $\mathbf{I}_{\mathbf{P O}}$, using their equation. A=2-log \% T . Also U.V - visble spectrophotometer was used for calculating the rate of degradation constant $\mathrm{K}_{\mathrm{d}}$. To follow-up the change in the average number molecular weight $\mathbf{M n}^{-}$wae determined by viscosity method using mark - houwink equation[ $\eta]=\mathrm{k}\left(\mathrm{M}_{\mathrm{v}}\right)^{\mathrm{a}}$ and the change in the average weight molecular weight $\boldsymbol{M} \boldsymbol{w}^{-}$by elevation high of the boiling point procedure .and molecular weight despersity $\mathbf{M w}^{-} / \mathbf{M n}$ - $^{-}$ Table.1. 
Table.1. mark - houwink equation constant.

\begin{tabular}{|c|c|c|c|c|}
\hline Polymer & Solvent & Temp C & K & A \\
\hline (Polyvinyl chloride (PVC & THF & $\mathbf{2 5}$ & ${ }^{4-101.38 ~ x ~}$ & $\mathbf{0 . 7 7}$ \\
\hline
\end{tabular}

Rate constant for Degradation of the complex $\left(K_{d}\right)$

The rate constant for degradation by oxidation with microwave radiation complex

$\left(\mathbf{K}_{\mathbf{d})}\right.$ Is calculated by using the equation of first order law

$\operatorname{Ln}(\mathbf{a}-\mathbf{x})=\operatorname{Ln} \mathbf{a}-\mathbf{K}_{\mathbf{d}} \mathbf{t} \ldots \ldots \ldots \ldots . .1, \quad$ as $\mathbf{a}=$ concentration of complex before radiation

$X=$ change in concentration of complex after time $t, t=$ irradiation time

$\mathbf{a}=\mathbf{A œ A} \mathbf{A}_{0}$, as $\mathbf{A}-$ oeadsorption at infinity time, $\mathbf{A}_{0}=$ adsorption $=$ .before irradiation

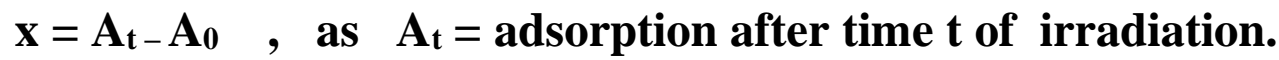

$\mathbf{A}-\mathbf{x}=\mathbf{A} \mathfrak{A}-\mathbf{A}_{\mathbf{0}}-\mathbf{-} \mathbf{A}_{\mathbf{t}}+\mathbf{A}_{\mathbf{0}}=\mathbf{A} \boldsymbol{A}-\mathbf{A}_{\mathbf{t}}$ 2

By substitution the value of $\mathrm{a},(\mathrm{a}-\mathrm{x})$, in Eq. No 1 and 2

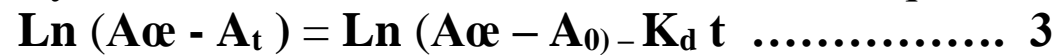

Drawing the relationship between the Ln (Ax - $\mathbf{A}_{\mathbf{t}}$ ) In contrast of irradiation time $(\mathrm{Sec})$ we get a straight line, slope is represents the ( $\left.-\mathbf{K}_{\mathbf{d}}\right)$. This indicates that fragmentation of the additives is from a first order

\section{RESULTS AND DISCUSSION}

Degradation of PVC is a two-stage process under the microwave irradiation of a sample, the initial mechanism is dehydrochlorination, where $\mathrm{HCl}$ molecules are

released, There is a general consensus that the intermediates in the degradation process are allylic sequences with progressively increased numbers of conjugated double bonds however, the mechanism of initiation, propagation, and termination steps is controversial. [21]. As evidenced by the following mechanism.

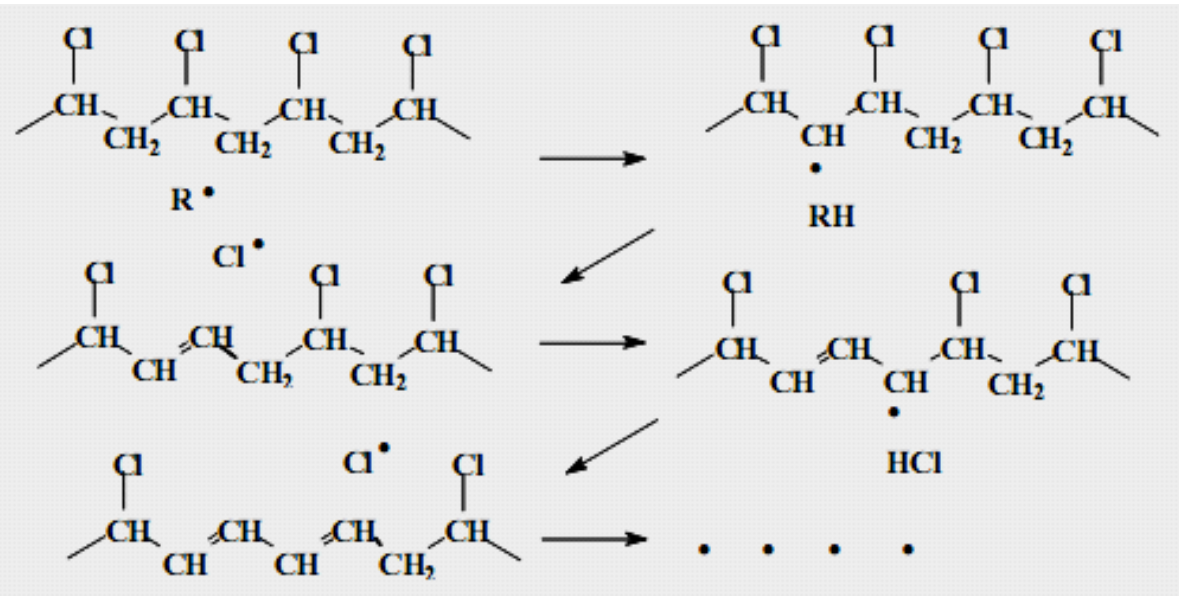


The major problem with this mechanism is that the chlorine atom is known to be so reactive as to be non-selective, data on model compounds showed that the allylic hydrogen atom, $<\mathrm{C}=\mathrm{CH}-\mathrm{CH}_{2}-\mathrm{CCl}<$ ), has only slightly higher reactivity toward abstraction by a chlorine atom that is free to diffuse throughout the polymer matrix than does a hydrogen atom from a secondary carbon $\left(-\mathrm{CH}_{2}-\mathrm{CCl}<\right)$.

The process could be initiated by microwave radiation ionizing radiation ,the oxidative radiolysis is accelerated by metals minute metallic contaminant inclusions can cause extreme oxidative degradation possibility of dehydrochlorination on PVC by a commercial microwave oven at the beginning of microwave irradiation experiment on PVC, the results of experimental, microwave irradiation act son PVC dehydrochlorination of PVC was developed by thermal degradation. The degradation of PVC was studied by following the changes in $-\mathrm{CH}_{2}-$ $\mathrm{CH}_{2^{-}}$stretch at (1604) $\mathrm{cm}^{-1}$ to polyene $\mathrm{I}_{\mathrm{PO}}$, Fig.( 11,12 ). The area of the peak at (1772) $\mathrm{cm}^{-1}$ is an indicate of chloro-keton, as the degradation progresses, the chloro-keton (their product from reaction between radicals $\mathrm{Cl}$ and atmospheric oxygen) is increased in intensity and long of peak, and degradation make that changes in $\mathrm{C}=\mathrm{O}$ stretch at (1727) $\mathrm{cm}^{-1}$ was represented of aliphatic-ketone, Table (1). The area of the peak increase in long and intensity, The percentage conversion of the reaction was therefore determined by following the increase in the integrated peak area $\mathrm{PO}$ and $\mathrm{C}=\mathrm{O}$ of PVC peak $(1604,1727,1772)$ respectively . Generally to offset any change in these bands due to spectrometer in stability. The peak area of the $(1604,1727,1772)$ band could be used quantitatively to determine the conversions of the degradation reaction without any internal referencing.

Microwave Degradation(MW) ; MW technology is environmentally friendly and The nature of $\mathbf{M W}$ heating is also much more efficient compared to resistance

heating, Microwaves lie between infrared radiation and radio waves in the region of the electromagnetic spectrum. More specifically, As all electromagnetic waves, microwaves consist of electric and magnetic field components, both perpendicular to each other. as it is well known that PVC has a high dielectric constant and high loss angles than other plastics, PVC absorbs microwave energy better than other plastic grades. The effects of microwave irradiation on PVC are considered that the polar material (PVC) is interacted with microwave power. The absorption of microwave powers is given by the following equation: [22].

$\mathbf{P}=\mathbf{k f t}^{2} \boldsymbol{\varepsilon} \tan \boldsymbol{8}=\mathbf{0 . 5 5} \mathrm{E}^{2} \mathbf{f} \boldsymbol{\varepsilon} \tan \mathbf{8} \times \mathbf{1 0}^{-10}$, where $\mathbf{P}$ is the absorbed MW power (W); $\mathbf{f}$ is frequency of applied $\mathbf{M W} ; \mathbf{E}$ is strength of 
electro- magnetic field $\boldsymbol{\varepsilon}$ is dielectric constant of materials $\mathbf{8}$ and is loss angle;

$\mathrm{k}$ is constant $\left(=2 \mu \boldsymbol{\varepsilon}_{0}=\mathbf{2} \boldsymbol{\mu} \times \mathbf{8 . 8 5} \times \mathbf{1 0}^{-12}\right)$. From Eq. above it can be stated that the absorbed microwave energy is depended on the strength of electro-magnetic field and dielectric characteristics of irradiating materials. The strength of electro-magnetic field is given as a function of the microwave power frequency. PVC has higher loss factor ( $\mathbf{E} \tan \mathbf{8}_{\text {) }}$ than that of other plastic species and it reveals that PVC has much advantages to absorb microwave than other plastic species. [23].

The degradation processes for PVC showed was change in the molecular weight due to the chain scissor cut the series of the polymers as a result for degradation and Table (3,4,5). And fig $(1,2,3,4)$.

Spectral study: showing Fig $(\mathbf{1 1}, \mathbf{1 2})$ show spectra for FT-IR for peaks absorbed for the reference sample with stretching $(\mathbf{1 7 2 7}-\mathbf{1 7 7 2}) \mathbf{c m}^{-1}$ for the $\mathbf{C}=\mathbf{O}$ group and shows all the peaks to other samples has been added to it a (Ni-BSEDA) complex are intensity and more absorbent and is indicating for degradation evented, and because the reaction between the product radicals and atmospheric oxygen to formation (peroxides, hydroxide), for peaks absorbed in stretching $(\mathbf{1 6 0 2}) \mathrm{cm}^{-1}$ to $-\mathbf{C H}_{2}-\mathbf{C H}_{2}-$ group for reference sample, and shows the all other peaks for sample which contain a complex salt are more adsorption and intensity compared with the reference sample.

showing spectra for $\mathbf{U} . \mathbf{V}$ absorption for different peak of PVC after and before radiation ,the adsorption of reference peak is low adsorption, but all adsorption peaks is higher than the reference, Table.[2. And fig (5-10)], that in the revealed an increace value of $I_{P O}$ and $I_{C O}$, with the increments of the concentration of (Ni-BSEDA) complex and radiation time.[Fig $(3,4)]$. Which the sample containing the highest concentration (0.1) have the largest value of adsorption. [Table ( 9 ), ( 10 )]. These results correspond to the values of the calculated degradation constant from slope the strength line fig $(\mathbf{1 1}-\mathbf{1 5})$, where the values are proportional with the increments the complex concentrations . where the $\mathbf{0 . 1 \%}$ percentage of the added complex to film given the highest value of degradation constant. While the addion of $\mathbf{0 . 0 2 5 \%}$ was gave the lower value for degradation constant Table ( 6 ) . This is consistent with previous studies of the degradation by MW irradiation.[24].

\section{CONCLUSIONS}

The results of this study showed that the degradation of PVC film is directly proportional to the concentration of complex which added in different percentage and with increasing time of microwave radiation. Also treating PVC with complex didn't stabilize or resist the energy of radiation, and Microwave radiation with $400 \mathrm{~W}$ in different times cause 
decrease in the molecular weight of PVC as a result of degradation, showing a change in color of the films from yellow to yellow - reddish and their color increase with increasing irradiation time increase, that mean the microwave radiation caused an oxidation of the surface, at first stage of degradation. also the average number of chain scissor increases when irradiation time(minute) and complex\% increase, in the other hand the use of microwave radiation in the degradation study is cheap and a short time.

Table. 2. U.V - Visible Absorption Value of P.V.C Film for Thickness ( $65 \pm 5$ ) micron with complex ( Ni-BSEDA( under microwave radiation with $400 \mathrm{~W}$.

\begin{tabular}{|c|c|c|c|c|}
\hline $\begin{array}{c}\text { MW. Irradiation } \\
\text { Time } \\
\begin{array}{c}\text { (Minutes) } \\
\text { \% Concentration }\end{array}\end{array}$ & \multicolumn{4}{|c|}{ Absorption } \\
\hline & 0.0 & 15 & 30 & 60 \\
\hline PVC & $\mathbf{0 . 2 7 1}$ & $\mathbf{0 . 5 4 1}$ & $\mathbf{0 . 8 4 2}$ & $\mathbf{0 . 9 5 7}$ \\
\hline $\mathbf{0 . 0 2 5}+$ PVC & $\mathbf{0 . 2 6 0}$ & $\mathbf{0 . 4 7 6}$ & $\mathbf{0 . 5 5 6}$ & $\mathbf{0 . 6 3 5}$ \\
\hline $\mathbf{0 . 0 3}+$ PVC & $\mathbf{0 . 2 5 6}$ & $\mathbf{0 . 4 3 5}$ & $\mathbf{0 . 4 8 6}$ & $\mathbf{0 . 5 4 6}$ \\
\hline $\mathbf{0 . 0 4}+$ PVC & $\mathbf{0 . 2 3 8}$ & $\mathbf{0 . 3 9 9}$ & $\mathbf{0 . 4 5 4}$ & $\mathbf{0 . 5 0 8}$ \\
\hline $\mathbf{0 . 0 5}+$ PVC & $\mathbf{0 . 2 1 2}$ & $\mathbf{0 . 3 5 6}$ & $\mathbf{0 . 3 8 2}$ & $\mathbf{0 . 4 1 1}$ \\
\hline $\mathbf{0 . 1}+$ PVC & $\mathbf{0 . 1 8 8}$ & $\mathbf{0 . 2 1 5}$ & $\mathbf{0 . 2 3 4}$ & $\mathbf{0 . 2 5 2}$ \\
\hline
\end{tabular}

Table.3. values of the molecular weight dispersity after degradation at 60 minutes in 400W of microwave radiation without additive of complex and chain scissor average

\begin{tabular}{|c|c|c|c|c|c|c|c|}
\hline $\begin{array}{l}\text { Irradiat } \\
\text { ion } \\
\text { Time }(m \\
\text { (inute }\end{array}$ & $M v \times 10^{4}$ & $(\mathrm{Mv})^{2} \times 10^{9}$ & $\begin{array}{c}\mathrm{dMv} \\
\mathrm{dt} \\
\mathrm{Mv}_{\mathrm{t}}{ }_{\mathrm{t}-\mathrm{M}} \mathrm{Mv}\end{array}$ & $\begin{array}{c}\text { Polymerizati } \\
\text { on Degree } \\
\text { Dp }\end{array}$ & $\begin{array}{l}1 \\
\mathbf{P}\end{array}$ & $\begin{array}{c}\text { Degradation } \\
\text { Degree } \\
\alpha \times 10^{-3}\end{array}$ & $\begin{array}{l}\text { Chain } \\
\text { scissor } \\
\text { average } \\
\text { (S) }\end{array}$ \\
\hline 0.0 & 5.078 & 2.578 & $\infty$ & 812.48 & 0.00123 & 0.0 & 0.0 \\
\hline 15 & 4.256 & 1.811 & 9.133 & 680.96 & 0.00146 & 0.23 & 0.186 \\
\hline 30 & 3.658 & 1.338 & 7.888 & 585.28 & 0.00170 & 0.47 & 0.381 \\
\hline 60 & 2.781 & 0.773 & 6.380 & 444.96 & 0.00224 & 1.01 & 0.820 \\
\hline
\end{tabular}

Table.4. values of the molecular weight dispersity after degradation at 60 minutes

in $400 \mathrm{~W}$ of microwave radiation with $0.05 \%$ of complex and chain scissor

average

\begin{tabular}{|c|c|c|c|c|c|c|c|}
\hline $\begin{array}{c}\text { Irradiation } \\
\text { Time(minut } \\
\text { (e }\end{array}$ & $\mathrm{Mv} \times 10^{4}$ & $(\mathrm{Mv})^{2} \times 10^{9}$ & 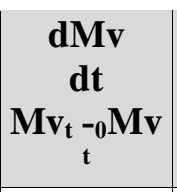 & $\begin{array}{c}\text { Polymeriz } \\
\text { ation } \\
\text { Degree } \\
\text { Dp }\end{array}$ & $\begin{array}{l}\mathbf{1} \\
\mathbf{P}\end{array}$ & $\begin{array}{c}\text { Degradation } \\
\text { Degree } \\
\alpha \times 10^{-3}\end{array}$ & $\begin{array}{c}\text { Chain } \\
\text { scissor } \\
\text { average } \\
\text { (S) } \\
\end{array}$ \\
\hline 0.0 & 5.078 & 2.578 & $\infty$ & 812.480 & 0.00123 & 0.0 & 0.0 \\
\hline 15 & 4.533 & 2.054 & 6.055 & 725.280 & 0.00137 & 0.14 & 0.113 \\
\hline 30 & 4.289 & 1.839 & 4.383 & 686.240 & 0.00145 & 0.22 & 0.178 \\
\hline 60 & 3.760 & 1.413 & 3.661 & 601.600 & 0.00166 & 0.43 & 0.349 \\
\hline
\end{tabular}


Table.5. quantitative products of chain scissor values for PVC with thickness ( $65 \pm 5$ ) micron and $0.05 \%$ complex at $1 \mathrm{~h}$ irradiation of $I_{0}=1.5 \times 10^{-8}$ intensity

\begin{tabular}{|c|c|c|}
\hline NO & Additives & SS $^{3-10 x}$ \\
\hline 1 & PVC & 14.9 \\
2 & Ni-) +PVC & 6.3 \\
\hline
\end{tabular}

Table.6. Valu of degradation rate for(Ni-BSEDA) complex to PVC film.

\begin{tabular}{|c|c|}
\hline$K_{d}(S e c)^{-1} \times 10^{-4}$ & Concentration \\
\hline 4.184 & 0.025 \\
\hline 3.587 & 0.03 \\
\hline 3.471 & 0.04 \\
\hline 2.980 & 0.05 \\
\hline 1.348 & 0.1 \\
\hline
\end{tabular}

Table.7. values of the Carbonyl Index Ico with different irradiation time.

\begin{tabular}{|c|c|c|c|c|}
\hline \multirow{2}{*}{ Wt\% of Additives } & \multicolumn{4}{|c|}{ Irradation time (minutes) } \\
\cline { 2 - 5 } & 0.0 & 15 & 30 & 60 \\
\hline PS & $\mathbf{0 . 1 9 6}$ & $\mathbf{0 . 5 9 0}$ & $\mathbf{0 . 6 8 1}$ & $\mathbf{0 . 8 7 4}$ \\
\hline PS 0.025 + & $\mathbf{0 . 1 8 2}$ & $\mathbf{0 . 5 5 1}$ & $\mathbf{0 . 6 3 9}$ & $\mathbf{0 . 7 0 5}$ \\
\hline PS 0.03 + & $\mathbf{0 . 1 6 6}$ & $\mathbf{0 . 5 0 3}$ & $\mathbf{0 . 5 8 7}$ & $\mathbf{0 . 6 5 7}$ \\
\hline PS 0.04 + & $\mathbf{0 . 1 5 2}$ & $\mathbf{0 . 4 5 6}$ & $\mathbf{0 . 5 0 8}$ & $\mathbf{0 . 5 3 2}$ \\
\hline PS 0.05 + & $\mathbf{0 . 1 4 3}$ & $\mathbf{0 . 3 8 2}$ & $\mathbf{0 . 4 4 2}$ & $\mathbf{0 . 4 8 6}$ \\
\hline PS 0.1 + & $\mathbf{0 . 1 2 5}$ & $\mathbf{3 1 7 . 0}$ & $\mathbf{0 . 3 4 6}$ & $\mathbf{0 . 3 9 7}$ \\
\hline
\end{tabular}

Table.8. values of the Polyene Index Ipo with different irradiation time

\begin{tabular}{|c|c|c|c|c|}
\hline \multirow{2}{*}{ Wt \%of Additives } & \multicolumn{4}{|c|}{ Irradation time (minutes) } \\
\cline { 2 - 5 } & $\mathbf{0 . 0}$ & $\mathbf{1 5}$ & $\mathbf{3 0}$ & $\mathbf{6 0}$ \\
\hline PS & 0.143 & 0.470 & 0.543 & 0.584 \\
\hline PS 0.025 + & 0.135 & 0.385 & 0.426 & 0.468 \\
\hline PS 0.03 + & 0.125 & 0.324 & 0.365 & 0.405 \\
\hline PS 0.04 + & 0.118 & 0.284 & 0.328 & 0.359 \\
\hline PS 0.05 + & 0.106 & 0.241 & 0.289 & 0.317 \\
\hline PS 0.1 + & 0.082 & 0.192 & 0.227 & 0.242 \\
\hline
\end{tabular}




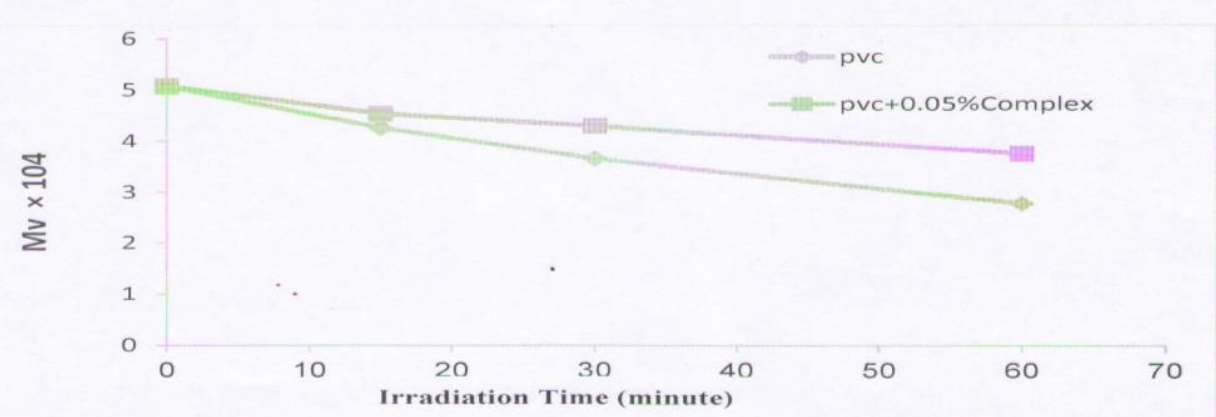

Fig.1.Relationship between MWV( viscosity) average of PVC and time irradiation with complex $0.05 \%$ and non-complex

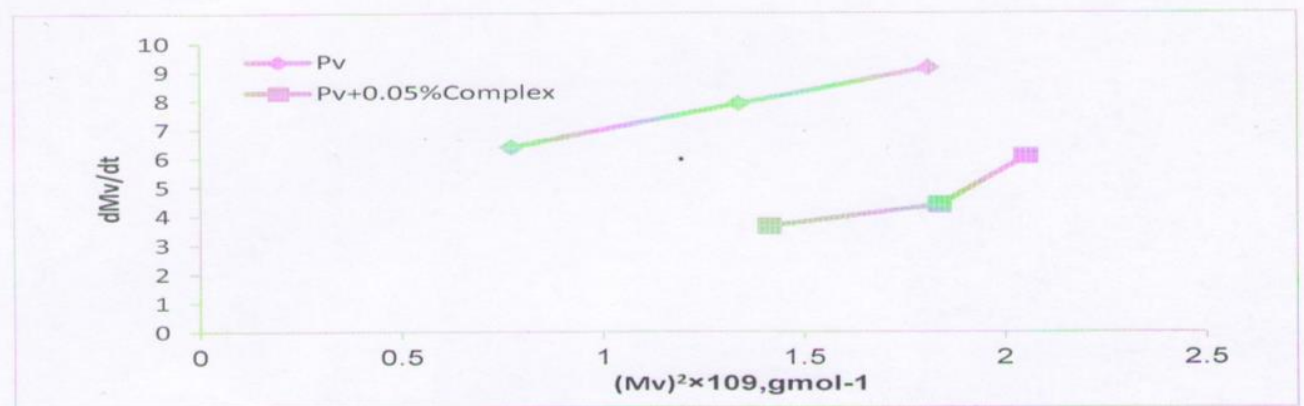

Fig.2. relationship between of decrease velocity in molecular weight average (dMv/dt) and square for molecular weight average with $0.05 \%$ complex and non-complex

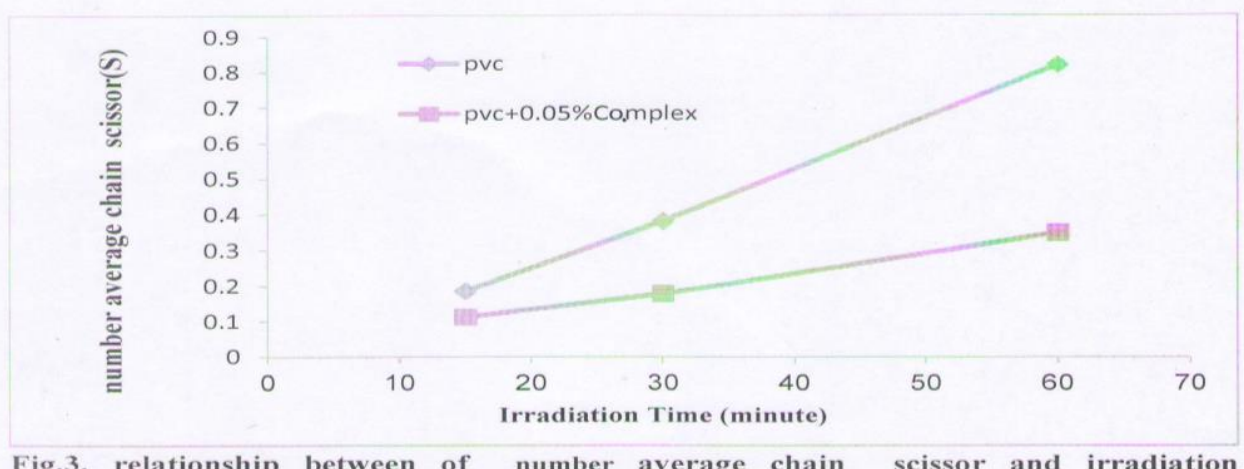
time(minute) with $0.05 \%$ complex and non-complex.

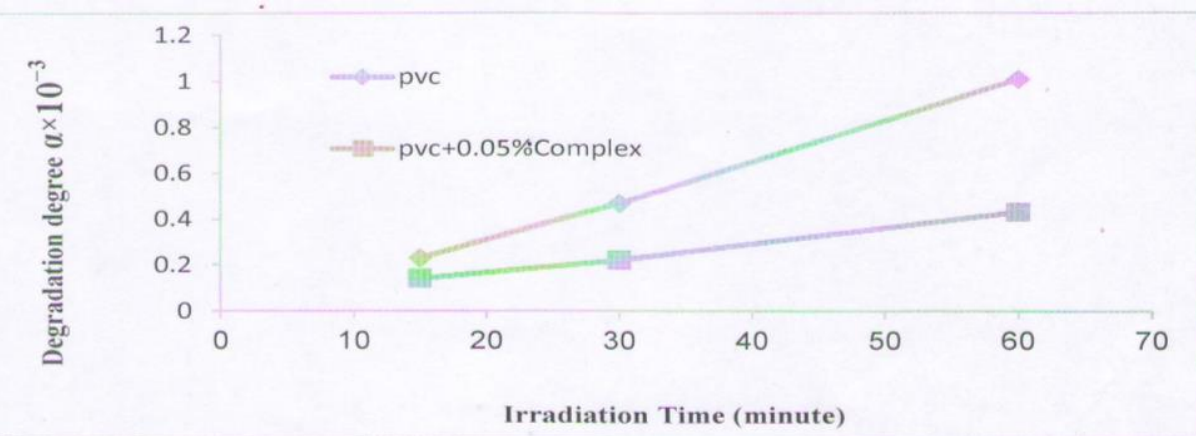

Fig.4. relationship between of Degradation degree and irradiation time with $0.05 \%$ complex and non-complex 


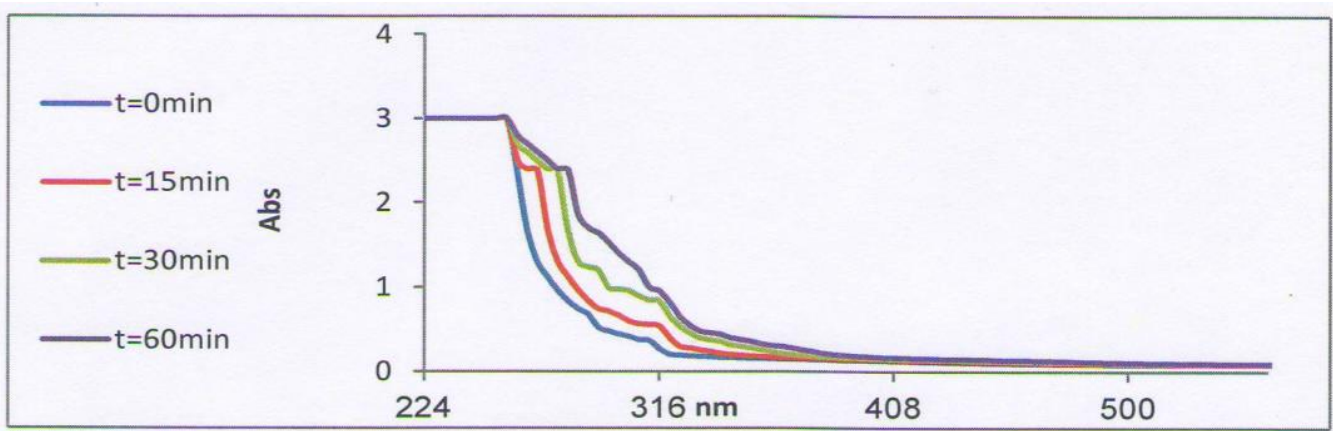

Fig. 5. U.V-Visible Spectra Change for P.V.C film without additives in different time for thickness ( $65 \pm 5$ ) micron

Irradiation Time (minute)

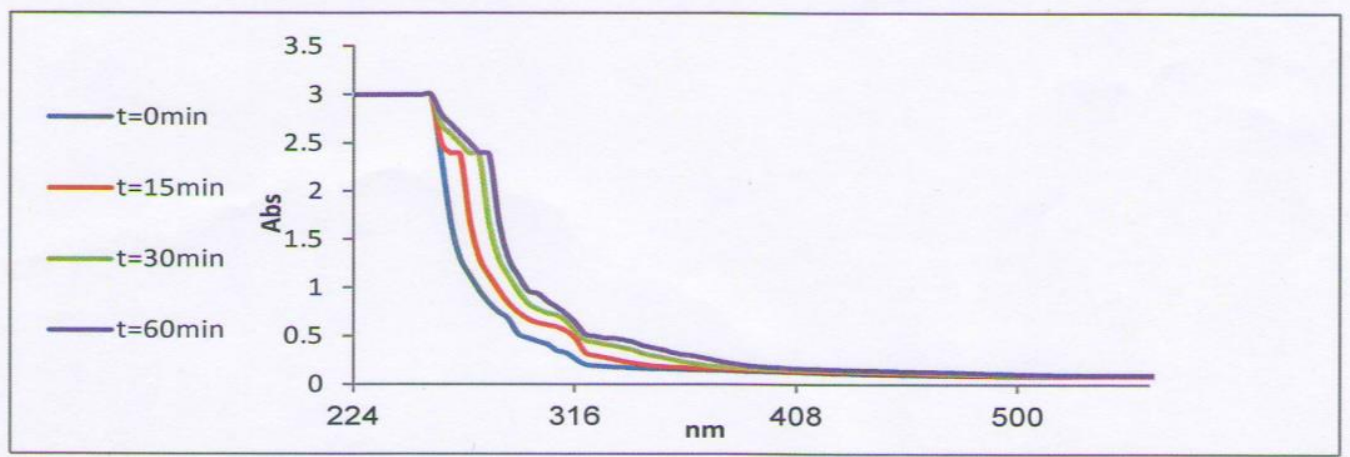

Fig.6. U.V-Visible Spectra Change for PVC Film With $(0.025 \%)$ Concentration for Complex (Ni-BSEDA) additives in different time for thickness $(65 \pm 5)$ micron.

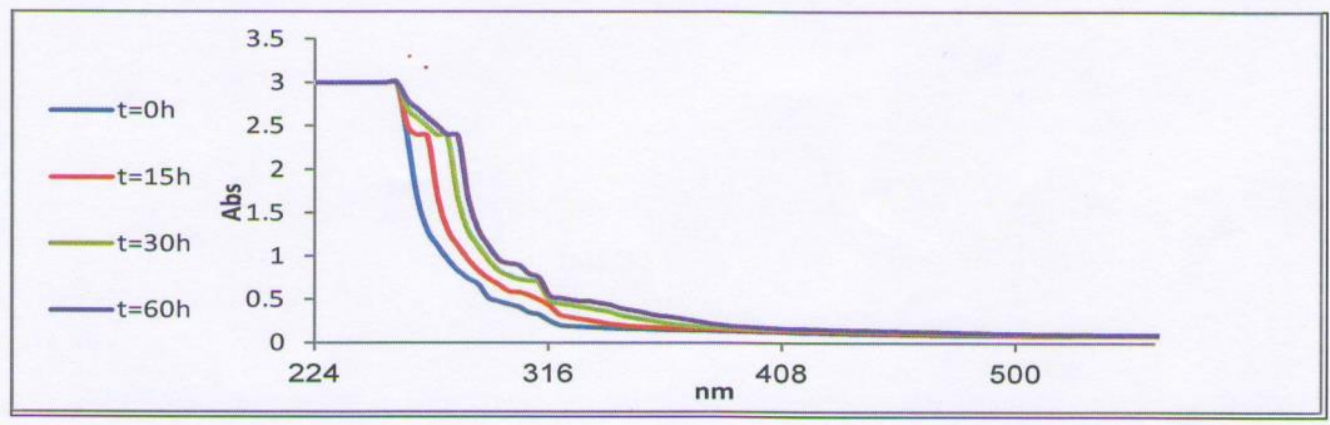

Fig. 7. U.V-Visible Spectra Change for P.V.C Film With $(0.03 \%)$ Concentration for Complex (Ni-BSEDA) additives in different time for Thickness ( $65 \pm 5$ ) micron.

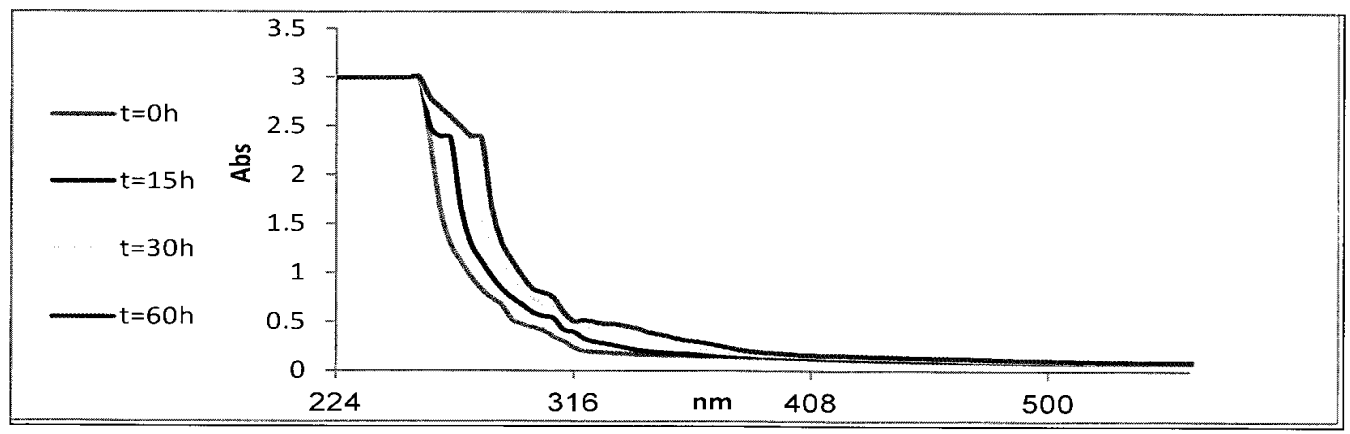

Fig. 8. U.V-Visible Spectra Change for P.V.C Film With $(0.04 \%)$ Concentration for Complex (Ni-BSEDA) additives in different time for Thickness ( $65 \pm 5$ ) micron. 


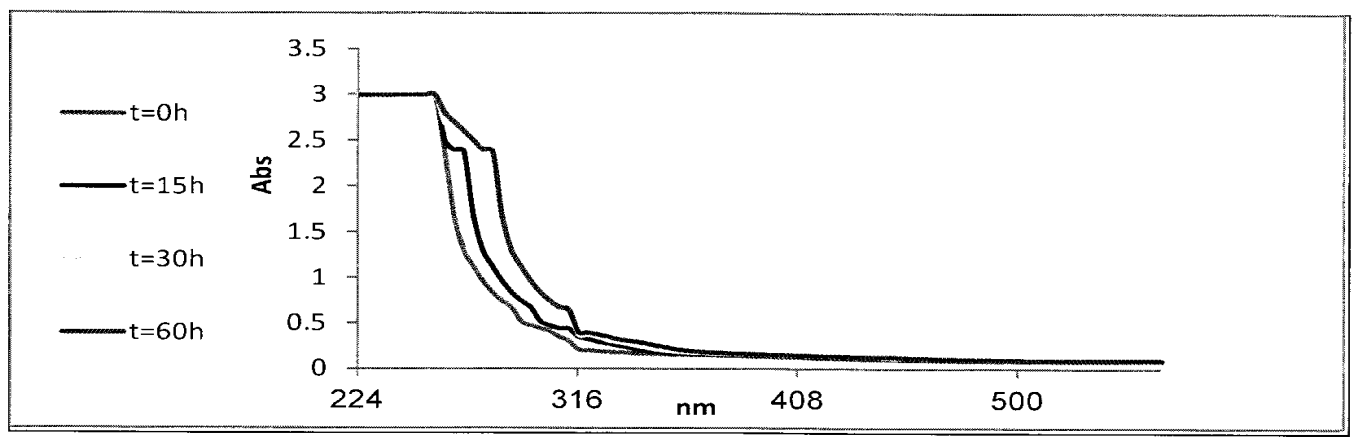

Fig. 9. U.V-Visible Spectra Change for P.V.C Film With $(0.05 \%)$ Concentration for Complex (Ni-BSEDA) additives in different time for Thickness ( $65 \pm 5$ ) micron.

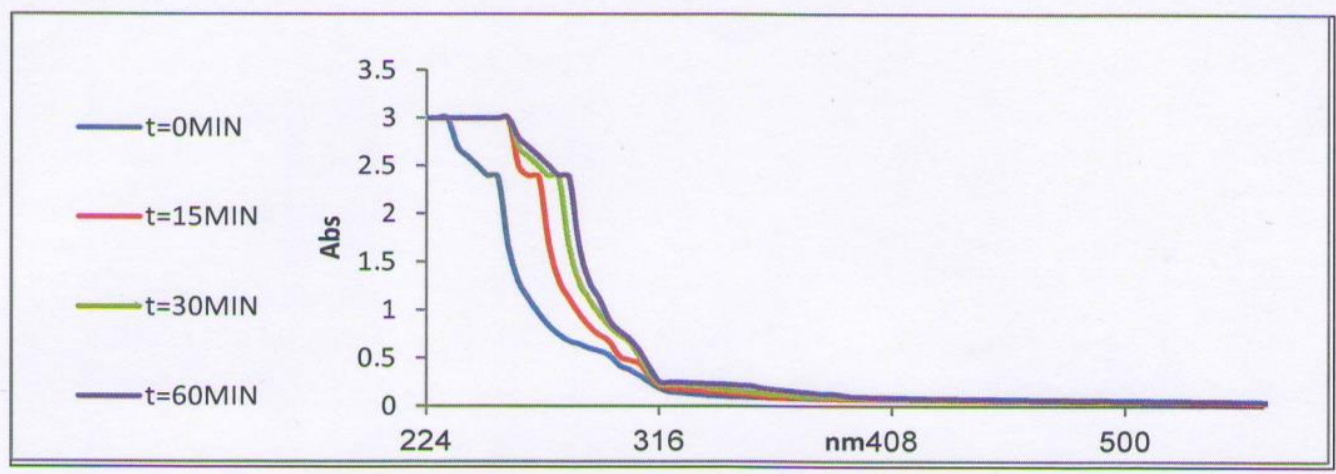

Fig.10. U.V-Visible Spectra Change for P.V.C Film With $(0.1 \%)$ Concentration for Complex (Ni-BSEDA) additives in different time for Thickness ( $65 \pm 5)$ micron.

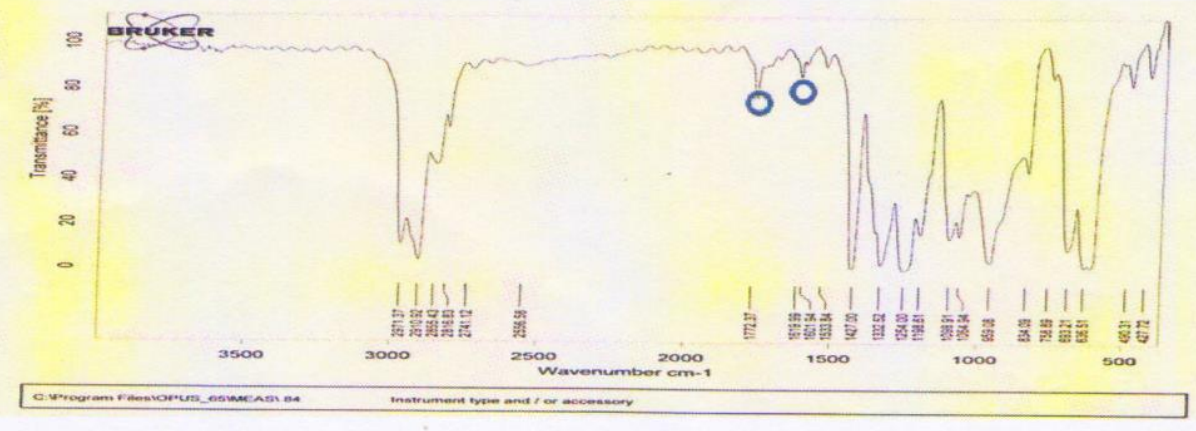

Fig. 11.FT-IR absorption spectra of PVC without additives after 60 minute of irradiation.

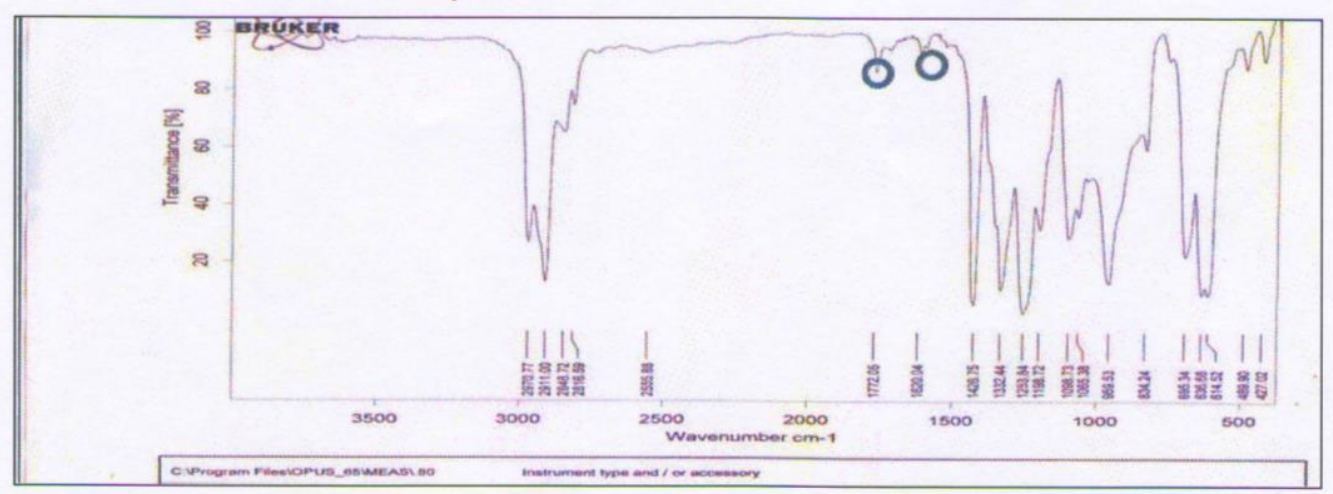

Fig.12.FT-IR absorption spectra of PVC with $0.1 \%$ complex after 60 minute of irradiation. 


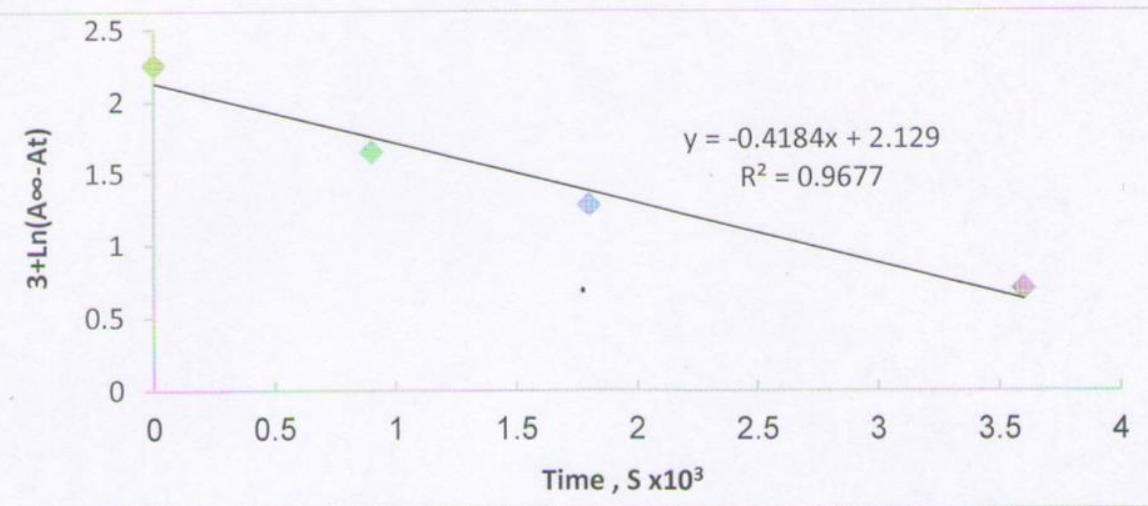

Fig. 13. The relationship between the natural logarithm of the complex (Ni-BSEDA) in P.V.C Film With $(\% 0.025)$ concenration for complex with time of irradiation.

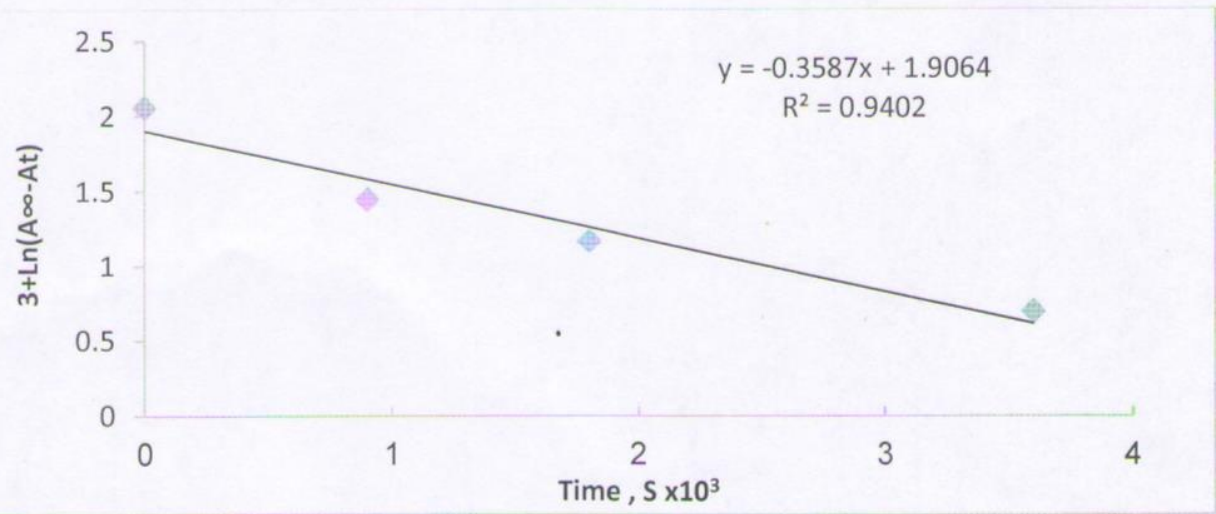

Fig. 14. The relationship between the natural logarithm of the complex (Ni-BSEDA) in P.V.C Film With $(\% 0.03)$ concen ration for complex with time of irradiation.

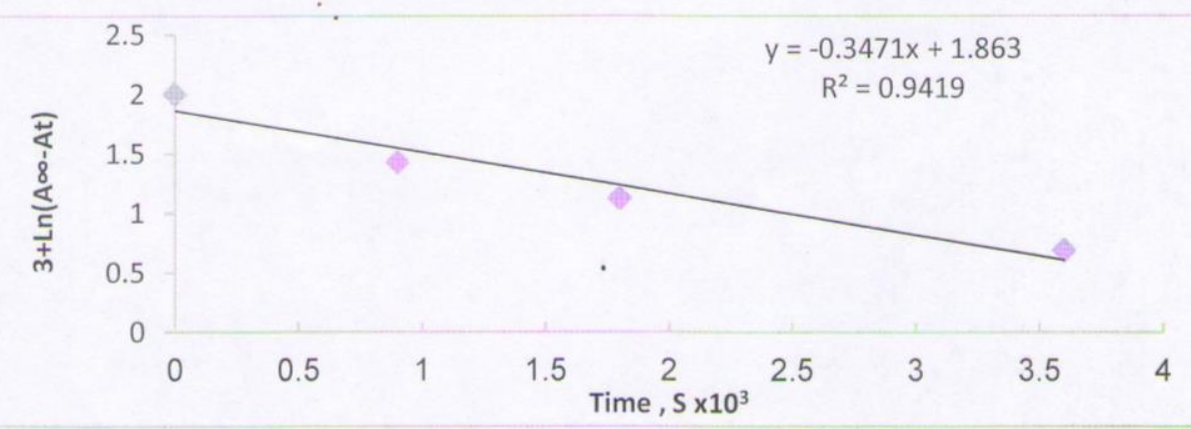

Fig. 15. The relationship between the natural logarithm of the complex (Ni-BSEDA) in P.V.C Film With (\%0.04) concenration for complex with time of irradiation. 


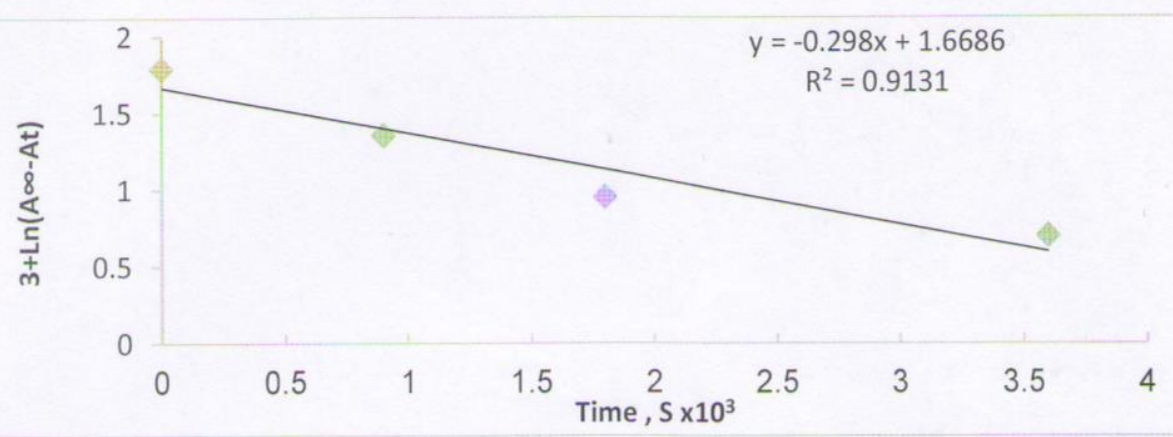

Fig. 16. The relationship between the natural logarithm of the complex (Ni-BSEDA) in P.V.C Film With $(\% 0.05)$ concenration for complex with time of irradiation.

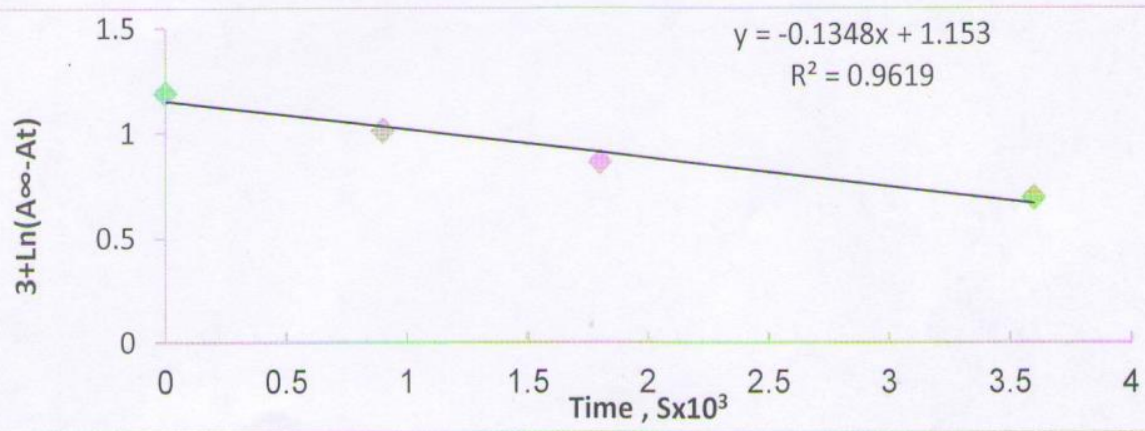

Fig. 17. The relationship between the natural logarithm of the complex (Ni-BSEDA) in P.V.C Film With (\%0.1) concenration for complex with time of irradiation.

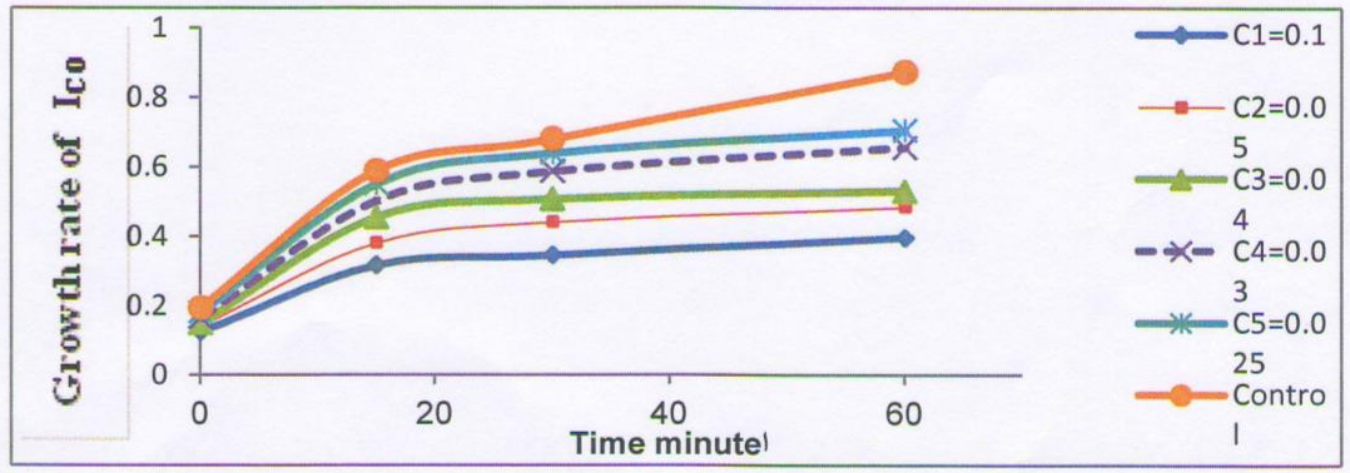

Fig.18. Relationship between adsorption of the carbonyl $I_{C O}$ and time Radiation

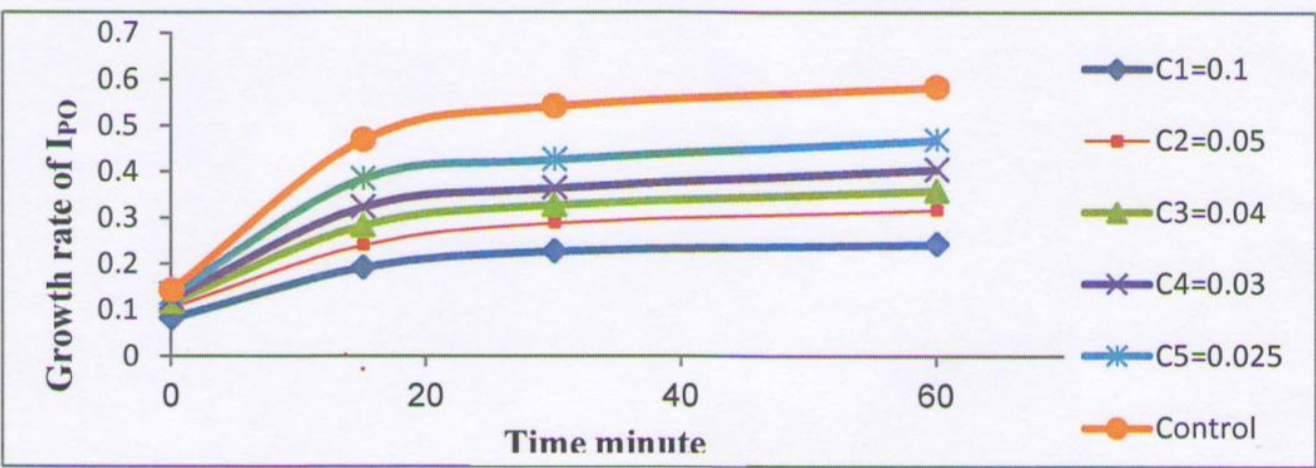

Fig.19. Relationship between adsorption of the Polyene $I_{P O}$ and time Radiation 


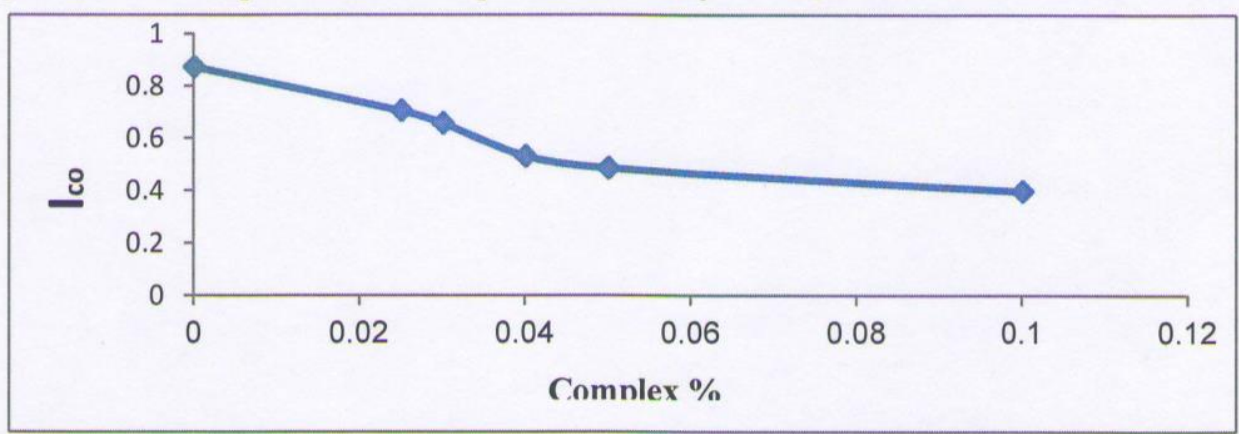

Fig.20. changed of Absorption index for $I_{C O}$ and concentration of (Ni-BSEDA) complex at 60 minute

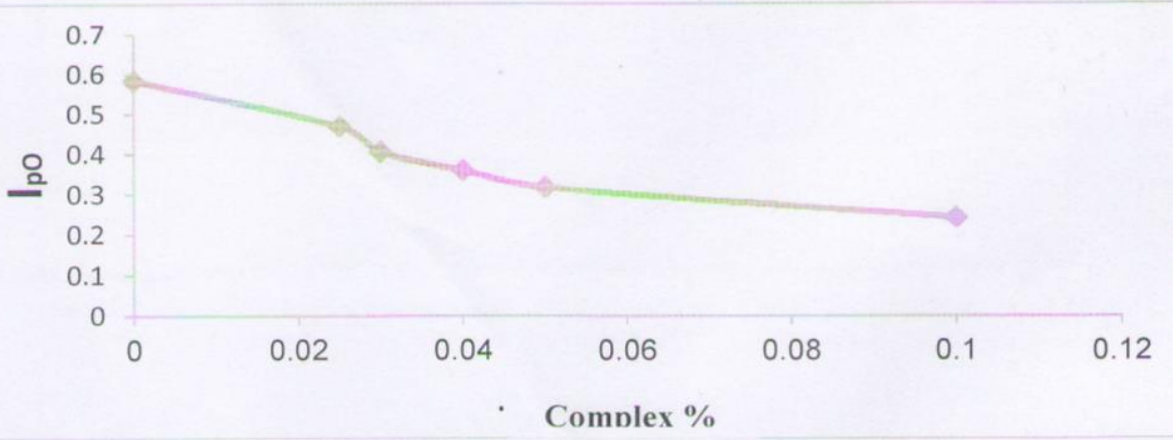

Fig.21. changed of Absorption index for IPO and concentration of (Ni-BSEDA) complex at 60 minute

\section{REFERENCES}

1) REFER1. Zhu HM, Jiang XG, Yan JH, Chi Y, Cen KF, Appl Pyrolysis, 82, 1-9, (2008.) (

2) Savrik SA, Erdogan BC, Balkose D, Ulku . J .Appl. Polym Sci, 116, 1811-1822, (2010).

3) Prachaya warakorn J, Khamsri J, Chaochan chaikul K, Sombat sompop N, J Appl .Polym Sci, 102, 598-606, (2006).

4) Mojtaba Saeedi , Ismaeil Ghasemi , and Mohammad Karrabi ,Iranian Polymer Journal ,20 (5), , 423-432, (2011)

5) Saburo Moriwaki ,Motoi Machida ,Hideki Tatsumoto , Yasufumi Otsubo , Applied Thermal Engineering 26,745 - 750 Elsevier Ltd. (2006)

6) Makiko Doi ,Kazuhiko Fukatsu , Ryota Shinohara ,Masataka Hai kibutu gakkaisi ,15, 294 - 301. (2004)

7) Seung Hwan Lee, Won Gu Lee, Bong Geun Chung ,Ali Khadem hosseini Macromol .Rapid Commun, 30,1382-1386, (2009)

8) Z. Zhao, Z. Li ,Q .Xia ,H. Xi ,Y .Lin , Eur .Poly. J . 44 , 1217. (2008) .

9) C. A . Puger, R .L . Carrier, B. Sun, K. S. Ziemer, D. D. Burkey, Macromol. Rapid Commun, 30, 126. (2009).

10) C. Oliver Kappe · Doris Dallinger ,Mol Divers 13:71-193,2009) 
11) Ondruschka $B$, Bonrath $W$ Microwave-assisted chemistry astock taking.Chimia 60:326-329, (2006).

12) Polshettiwar V, Varma RS Aqueous microwave chemistry ,Chem .Soc Rev37:1546-1557 (2008)

13) Coquerel Y, Rodriguez J , Microwave-assisted olefin Metathesis .Eur. J. Org. Chem 1125-1132 (2008) .

14) Vijayalakshmi , S . P .; Madras , G .Polym Degrad Stab , 84, 341 (2004).

15) G. L. Liu, D.W. Zhu, S. J. Liao ,L. Y . Ren ,J .Z. Cui, And W. B. Zhou , Journal of Hazardous Materials ,vol .172, no .2-3 ,pp. 1424 1429, (2009)

16) M .H .Habibi ,M .N .Esfahani , and T. A. Egerton ,International Journal of Photoenergy ,vol .2007, Article ID 13653 , 8 pages , (2007)

17) D. Nabi ,I .Aslam ,and I. A. Qazi, Journal of Environmental Sciences ,vol. 21 , no .3, pp . 402- 408, (2009).

18) Valhlstrom, W., Putting Hipot out to Pasture, EC\&M 102: 10, 20-24 (2003).

19) SATOSHI HORIKOSHI, FUKUYO HOJO,AND HISAO HIDAKA. Environ. Sci. Technol., 38, 2198-2208, (2004) .

20) Guang-Hua Zhang, Jun-Feng Zhu, A .Okuwaki, 50 231-239 (2007).

21) Marimuthu A.and Giridhar Madras, Ind .Eng .Chem .Res, 47,7538 -7544 ( 2008) .

22) Pedro E. sanchez-Jimenez, Luis A .Perez- Maqueda ,Antonio Perejon, Jose M. Criado , Polymer degradation and stability, 95, 733-739, (2004)

23) Saburo Moriwaki , Motoi Machida ,Hideki Tatsumoto, Dehydrochlorination of poly(vinyl chloride) by microwave irradiation Applied Thermal Engineering 26, 745 -750 , (2006). 